\title{
Life emergent
}

\section{Evan Thompson weighs up a treatise that explores the dynamics of matter and consciousness.}

$\mathrm{H}$ ow is mind - cognition and consciousness - related to biological life? Current thinking in cognitive science suggests that living and cognitive systems share basic organizational properties, such as being autonomous or self-producing and self-sustaining. Anthropologist Terrence Deacon's Incomplete Nature is a welcome contribution to this field.

Deacon draws on thermodynamics, complex-systems theory and biology to show how we can understand the characteristics of mind in relation to life, and those of life in relation to inanimate matter, without losing sight of their continuity. He plots the ways in which non-living physical systems can self-organize and evolve into living systems, and how living systems can evolve into cognitive systems.

Deacon takes his guiding idea from one of my favourite chapters of a classic Chinese philosophical text from the fourth century BC, the Tao Te Ching: "Pots are fashioned from clay/But it's the hollow that makes a pot work." Similarly, Deacon sees the 'constitutive absence' as functional, a defining property of life and mind. Living things are dynamically organized around ends, such as finding nourishment; and minds are dynamically organized around meanings, such as anticipated future events. And like the hollowed interior of the pot, these ends and meanings are both functional and absent, in the sense that they affect a system's behaviour, yet are not material parts of it.

This idea leads Deacon to offer a new twist on theories of how inanimate matter can self-organize and evolve to become living, and how living systems can evolve to become cognitive. To reflect absence, he introduces the concept of constraints in a dynamical system. For example, water molecules heated in a pan organize into rotating convection cells, with their motions constrained by the geometry of the cells. In this system, absence is the variety of alternative paths the water molecules could have taken. Yet the system, Deacon says, depends on their absence.

Applying this idea to the emergence of life, Deacon considers autocatalytic molecules. These copy themselves by catalysing their own production, and can collectively build systems that evolve to have a metabolism and reproduce. In Deacon's version, autocatalytic molecules manufacture by-products that self-assemble into a container that then houses those reactions. Again, the absence on which the system depends is the other ways in which the molecules could have been distributed.

Such self-generating systems, for Deacon, already have a minimal kind of self. Multicellular organisms have a more complex bodily self

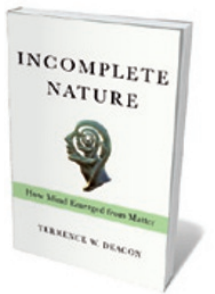

Incomplete Nature: How Mind Emerged from Matter

TERRENCE W. DEACON W. W. Norton: 2011. 624 pp. $\$ 29.95$, $£ 19.99$ than these systems, and animals with brains have a cognitive self because the brain must constantly represent its own ongoing activity in relation to the body and to the outside world. As Deacon unfolds this narrative, he provides perceptive accounts of key notions, such as information and emergence - how complex systems arise from many comparatively simple interactions.

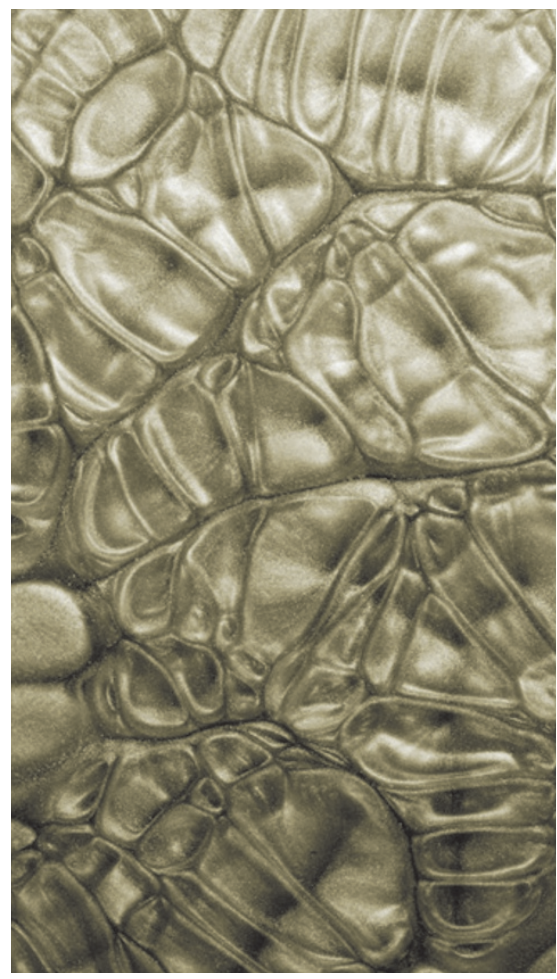

The geometry of convection cells in heated liquid.
But Incomplete Nature has shortcomings. Deacon doesn't discuss other theorists who have given similar accounts of life and mind, such as Alicia Juarrero in Dynamics in Action (MIT Press, 2002) or myself in Mind in Life (Harvard University Press, 2007). He also sometimes overemphasizes the differences between his views and those of the theorists he does cite.

Deacon stumbles at two crucial junctures - his explanations for the emergence of meaning and for the emergence of consciousness. The problem of meaning is the problem of how it is possible for certain physical phenomena, such as brain states, to have content or to be 'about' something beyond themselves.

Deacon's answer is not easy to decipher. Roughly, he seems to be saying that certain states of a self-generating system acquire content when they correlate reliably with features of the environment that are useful to that system. For example, a system that needs molecules from the environment in order to reproduce 'interprets' the presence of these molecules as meaning that the environment is conducive to reproduction. But this seems little more than metaphorical. As many philosophers have shown, meaning cannot be reduced to such processes.

With consciousness, Deacon says that sentience - the capacity to feel - arises from a system being self-sustaining and goal-directed. So he sees individual cells as sentient. But, as he explains, an animal's sentience is not the sum of the sentience of its individual cells: the nervous system creates its own sentience at the level of the whole animal. Yet Deacon doesn't get to grips with the hard problem of explaining why and how we and other animals have conscious experience.

Simply pointing to the neural activity associated with sentience is not enough to answer this question. What we need to know is why this activity feels pleasant or painful to the animal, instead of being an absence of feeling. In my view, Deacon's error is not that he has no answers to such questions (no one does), but that he fails to recognize them.

On the empirical side, Deacon's discussion also falls short. He doesn't explore the neuroscience literature showing how large-scale brain activity is related to consciousness, and makes no use of writings that relate these findings to how we experience emotion, time and the self.

Although incomplete in these ways, Incomplete Nature contains many rewarding thoughts about life and mind and their place in nature.

Evan Thompson is professor of philosophy at the University of Toronto, Ontario M5R 2M8, Canada.

e-mail:evan.thompson@utoronto.ca 